1 Accepted version Ibis $20^{\text {th }}$ Mar 2016

2 Running head: Habitat generalism in migrants

3

4

5

6

\title{
Temperate migrants and resident species in Afro-tropical savannahs show similar levels of ecological generalism
}

\author{
Sam T. Ivande* 1,2 and W. Cresswell ${ }^{1,2}$ \\ ${ }^{1}$ School of Biology, University of St Andrews, St Andrews, KY16 9TH, UK \\ ${ }^{2}$ A.P Leventis Ornithological Research Institute (APLORI), Jos, Nigeria \\ *Corresponding author: ivande.sam@gmail.com
}

How specific an animal's habitat requirements are will determine its ability to deal with anthropogenic climate and habitat change. Migratory birds are observed as being particularly vulnerable to such change, but theory predicts that they should be largely generalist. This prediction was tested with the aim to confirm whether migratory Palearctic birds wintering in the savannah biome of Africa were relatively generalist compared to taxonomically and ecologically similar Afrotropical resident species in terms of habitat use. The degree of specialization of these species groups to certain habitat characteristics was assessed and compared by calculating the relative occurrence of the species along habitat gradients, where wide occurrence would indicate generalism and narrow occurrence implies specialism. Palearctic migrants as a group could not be clearly distinguished as generalists relative to Afrotropical residents with respect to habitat attributes. The only indication of greater flexibility in Palearctic migrants was a significant tendency to utilize habitats over a larger latitudinal range. The results probably confirm that migrants are generalists but not particularly more so than taxonomically similar resident species that also occur over a wide range of habitat types within the savannah biome. Availability of specific habitat requirements on the wintering grounds in Africa is therefore unlikely to be a primary limiting factor for many migrant bird species.

Key-words: habitat specialization, generalists, Palearctic migrants, Afrotropics, migration, habitat use, distribution 


\section{Introduction}

29 Understanding habitat specificity in organisms is important in explaining and predicting how

30 they may respond to environmental change. Species may be closely associated with one or

31 more habitats or habitat characteristics and are often described as specialists or generalists

32 depending on the range of such habitats that they are able to exploit and their capability and efficiency at using each one ( MacArthur 1972, Julliard, et al. 2006). Whereas specialists may only occupy relatively small niches (i.e. exploit only a small subset of habitat characteristics) but utilise them very efficiently, generalist species may alternatively occupy larger niches, exploiting a wider range of resources but sometimes with relatively lower efficiency (MacArthur 1972, Wilson and Yoshimura 1994). Generally, habitat specialists, which are also associated with lower dispersal ability, are thought to be more negatively affected by environmental stochasticity. They are also thought to respond more to local ecological and habitat processes in contrast to generalist species which generally have broader geographic distributions as well as good dispersal and colonization abilities (Julliard, et al. 2006, Shubha, et al. 2009, Clavel, et al. 2011, Sokolov, et al. 2012).

In environments where species' requirements may overlap, differences in habitat specialization could provide a mechanism for the coexistence of potentially competing species and thus have implications for the dynamics of such communities (Morris 1996). This study investigates the relative degree and difference in habitat specialization patterns using an avian community of migratory and resident species in an Afrotropical savannah zone where this may potentially be important in fostering coexistence. Migratory species/individuals in these communities have often been described as habitat generalists, thought to adopt generalist strategies and exhibit ecological flexibility in order to 'fit in' with the 'superior and

51 dominant' resident communities where these migrants were also seen as 'visitors' or

52 'temporary invaders' (Herrera 1978, Sinclair 1978, Leisler 1992). Consequently, observations 
of migrants' occurrences in more open and peripheral habitats, combined with their relatively

higher foraging speeds and a tendency to use a wider range of foraging tactics have largely also been interpreted as evidence that migrants are flexible and generalists (Salewski, et al. 2002, Salewski, et al. 2003, Salewski and Jones 2006, Salewski, et al. 2007, Jones, et al. 2010). Furthermore, in a recent review, Cresswell (2014) argued that a generalist strategy is the most likely to be selected for in migrants considering the potential for stochastic processes to affect the initial selection of site at a large scale for an animal migrating for the first time. The debate however remains as to whether these observed attributes and distribution patterns are consequences or precursors for migration behaviour (Salewski and Jones 2006).

As well as being of theoretical interest with respect to the evolution of migration and the structuring of communities that contain migrants, the degree of habitat specialisation shown by Palearctic migrants is relevant to their conservation. This is especially important given reports of substantial declines in the populations of some Palearctic migrant species. In many cases, connections have been made between these declines and the changing habitat and climatic conditions in their wintering quarters (Ockendon, et al. 2012, Ockendon, et al. 2014, Vickery, et al. 2014) which appear to be related to the degree to which the concerned migratory species or populations are specific in their use of these habitats. For instance, population declines in the 1970 s were greatest in species that specifically utilise the dry woodland and scrub habitats of the Sahel during the winter periods (Baillie and Peach 1992, Walther, et al. 2011, Atkinson, et al. 2014). In recent years however, greater declines have largely been observed for trans-Saharan migrant species utilising the more humid Afrotropical Guinea savannah habitats (Vickery, et al. 2014). Investigating habitat specificity in migrants is therefore not only important to help understand the underlying mechanisms of these declines and how this may be related to the degree of specificity in habitat use, but 
could also be vital in informing appropriate management strategy and policy necessary for the successful conservation of these species.

80 This study explores at a landscape scale, the relative distribution and habitat use of Palearctic migrants and Afrotropical resident species in the Guinea and Derived savannah habitats in Nigeria, West Africa. The degree of specialization of these two species' groups to habitat characteristics in this area are evaluated and compared, testing the hypothesis that migrants will to a greater degree be more generalist - use a wider range of the habitats within the savannah - than taxonomically similar residents in the Afrotropics. We adopt a relatively straightforward approach to test this hypothesis where we compare the occurrence across habitat gradients of migrant species versus taxonomically and ecologically similar resident species. We use all possible species that provided sufficient records to allow statistical testing, and test whether there were any significant biases due to not considering rarer species and due to potential detectability differences between migrants and resident species.

\section{$91 \quad$ Materials and methods}

\section{Study area}

This study was carried out in the Guinea and Derived savannahs in Nigeria, West Africa. The

Guinea savannah is located between the mainly arid and open Sudan and Sahel savannahs to the north and the more humid and densely vegetated rainforests to the south. Together with the Derived savannah (which is essentially cleared and logged portions on the northern edge

97 of the rainforest and representing an extension of the savannah into the rainforest), the

98 Guinea savannah covers about $50 \%$ of the Nigerian landscape and forms an ecological and transitional belt of vegetation across the middle regions of Nigeria. Vegetation in this

100 ecological zone is dominated by broad-leaved and short-boled trees up to $15 \mathrm{~m}$ high, with a

101 heterogeneous mosaic of habitats ranging from isolated gallery and riparian forests, open

102 wood/shrublands and open grasslands. Anthropogenic and climatic effects are severe: fierce 
annual fires in the dry season have allowed fire-resistant species to predominate while

104 continuous clearing for agricultural lands and intense grazing continues to reduce and 105 fragment this area (Adegbola and Onayinka 1976, FORMECU 1998, Abbas 2009). Survey areas (habitats) were selected to represent the entire range of habitats available in terrestrial

107 Guinea savannah from highly anthropogenic habitats such as cleared farmland through to 108 relatively pristine Guinea savannah woodland with high densities of natural vegetation (e.g. 109 see the variation illustrated in Fig. A1 supplementary material).

\section{$110 \quad$ Field survey}

111 Bird surveys and habitat characterization were conducted during the northern winters of

112 2011/2012 and 2012/2013. The point transects method was used to record birds and involved

113 counts of birds from several points which were located at regular intervals along a given

114 transect. A total of about 630 points were surveyed, spread across 12 survey sites which were

115 distributed over a 4 degree latitudinal range $\left(6-10^{\circ} \mathrm{N}\right)$ in the Guinea savannah (Figure 1,

116 Supplementary material Table A1). There were at least 3 survey sites per latitude and at least

1173 transects spread across different habitat types within a survey site. Eighteen point transects

118 spread across six survey sites were surveyed once every month in the first winter period from

119 February - May 2012. Three surveys were conducted during the second winter; one survey in each period of September-December 2012, January - February 2013, and March - April 2013 across 24 transects in 8 survey sites ( 3 out of 6 of the first winter sites plus 5 new sites). Presence and absence of birds were recorded for 5 minutes at each point which had a radius of $50 \mathrm{~m}$ and these were located at $100 \mathrm{~m}$ intervals along the transects of between $1.5-2 \mathrm{~km}$ in

124 length. All bird counts were conducted during the early hours of the day just after dawn, usually from about 06:00 hours for about three hours. For every sighted bird, the distance from the observer who was at the centre of the point was recorded using a Nikon 550 laser range finder. The geographical coordinates was recorded at the centre of each point count 
variables characterizing the vegetation density/cover, structure/height profile, anthropogenic

$130 \mathrm{impact} /$ disturbance and latitudinal/geographical distribution of habitats were also recorded at

131 each point location (Supplementary material Table A2) during every survey visit. Vegetation sampling during every survey visit allowed for any changes in the characteristics of the vegetation with season to also be recorded. For example a point that was visited early in the season with a dense grass cover could eventually have very low to no grass cover later in the season especially in areas where the vegetation is seasonally burnt.

\section{Data analysis}

137 All statistical procedures and tests were conducted in $\mathrm{R}$ version 3.1.0 statistical software ( $\mathrm{R}$

138 Development Core Team 2014). All migratory passerine species as well as taxonomically-

139 related and ecologically similar Afrotropical resident species were selected from all recorded

140 species for the purpose of comparison and analysis. An initial total of 35 species from five 141 families were considered for this analysis including 11 Palearctic species recorded during 142 point count surveys and 24 Afrotropical species from the same families, with similar sizes,

143 from similar foraging guilds and/or with similar foraging strategies as the Palearctic species.

144 Ten of these 35 species (fully listed in Supplementary material Table A3) had very limited 145 occurrence and were recorded from less than 10 points (i.e. less than $2 \%$ of the total surveyed 146 points and less that $15 \%$ of the survey points at a site) throughout the study area and period.

147 These were excluded to give a second set of 25 species (Supplementary material Table A3 \&

148 Table 1). This selection did not alter the abundance/occurrence ratio between migrants and

149 residents: a $t$-test indicated that the difference in abundance/occurrence ratio of migrants and 150 resident birds before and after the exclusion was not statistically significant (with the group of 35 species - Abundance: $t=1.4$, d.f. $=14.1, P=0.19$ and Occurrence: $t=-1.4$, d.f. $=12.7$, $P=0.18$ and with the group of 25 species - Abundance: $t=-1.6$, d.f. $=10.7, P=0.13$ and

153 Occurrence: $t=-1.7$, d.f. $=9.1, P=0.13$ ). Consequently, a total of 25 species from five

154 families recorded from at least 10 different points were considered to have provided 
sufficient records to allow statistical testing and were used for this analysis (note that

156 analyses using all 35 species are largely the same species i.e. no significant differences in

157 habitat specialization save for differences in latitudinal distribution). This consisted of 8

158 Palearctic migrant and 17 Afrotropical resident species. These Afrotropical species were from

159 the same taxonomic families and foraging guilds and have similar foraging strategies as the

160 recorded Palearctic species (Fry, et al. 2000, Urban, et al. 1992, Urban, et al. 1997).

161 We tested whether there were detectability differences between the migrant and resident

162 groups by comparing the frequency distribution of distances that each species was recorded 163 during a point count, with species classified into the two groups. A Generalized Linear Mixed

164 effects Model (GLMM) was carried out using the library lme4 in R with the model structure

165 of: distance recorded $(<50 \mathrm{~m})=$ migratory status (resident or migrant) + year + species

166 identity (as a random effect). There was no significant difference in detectability (distance at

167 which a bird was recorded) by migratory status for either the 35 species data set, or the

168 reduced 25 species data set used in subsequent analyses (migratory status: $-0.63+/-1.3$ SE

169 for residents, $\chi^{2}=0.3, \mathrm{P}=0.58, \mathrm{~N}=1414$; or $-0.31+/-1.2$ SE for residents, $\chi^{2}=0.1, \mathrm{P}=$

$1700.74, \mathrm{~N}=1261$, respectively). The models were very robust to violation of assumptions with

171 a reasonable normal distribution of residuals, no evidence of heteroscedasticity or outliers;

172 truncation to $<50 \mathrm{~m}$ only reduced sample sizes by $11 \%$ for both models and only $<1 \%$ and $\mathrm{c}$.

$1735 \%$ of variance for fixed and random effects respectively was accounted for in both models.

174 Therefore there was no evidence of any likely confounding effects from variable

175 detectability: migrants and resident species had similar recorded distances.

176 We adopted a simple definition of specialists as species utilizing a narrow range of resources

177 and generalists as those that use a wide range of resources. Therefore, specialists would use 178 and be associated with only a small and specific range of the habitat characteristics measured

179 and hence will show little variability for these habitat variables. The reverse would be the 180 case for a generalist species i.e. associated with a relatively higher variation in measured 
habitat variables. A Habitat Specialization score (HS score) was calculated based on the

182 degree of variation (represented by the standard deviations) observed in the range of habitat

183 characteristics from points where each species was recorded. This involved, in the first

184 instance, a Principal Component Analysis (PCA) using the prcomp function and a varimax

185 rotation to summarise all recorded 13 habitat variables across all points surveyed into three

186 composite variables i.e. the top three components from the PCA (Supplementary material

187 Table A4). Bartlett's test of sphericity, which tested the overall significance of all the

188 correlations within the correlation matrix of the habitat variabes indicated that it was

189 appropriate to summarise the dataset in a PCA (Bartlett's test: $\chi^{2}(78)=2170.4, P<0.001$ ).

190 The Kaiser-Meyer-Olkin (KMO) measure of sampling adequacy further indicated sufficient

191 relationships among these variables $(\mathrm{KMO}$ criterion $=0.75)$ to proceed with the analysis.

192 For each species, PCA scores for all points where it was recorded (i.e. its presence points)

193 were then extracted and the standard deviations (sd) calculated to give a measure of its

194 variability in habitat use with respect to the composite variable. This sd value was divided by

195 an overall standard deviation of all habitat scores from every point that had been surveyed to

196 obtain a proportion of the variability in that habitat characteristic associated with the

197 occurrence of that species. These proportions were then scaled between 0 and 1 to give a

198 habitat specialization score for each of the three principal components and for each species. A

199 zero HS score represents the most specialized species in the group with the least specialized

200 species i.e. a generalist, showing greatest habitat flexibility with a score of 1 (i.e. occurred in

201 all habitats). Habitat specialization scores of migrants and Afrotropical residents for all three

202 principal components were compared for significant differences using a $t$-test.

203 In a second approach, HS scores were derived following a similar process as above but using

204 the values of the 13 unsummarized habitat variables instead of the scores for the composite

205 variables derived from a PCA. We analysed the individual variable values as well as the

206 composite scores to better understand the biological significance of the habitat variation. All 
values were also compared with a t-test between resident and migratory birds for each of

208 these 13 unsummarised habitat variables. A Bonferroni multiple-comparison correction was

209 carried out by dividing each $p$ - value by the total number of tests (i.e. there were $13 t$-tests,

210 so $0.05 / 13)$ to set a new significant threshold value (0.004) to account for the probability of

211 increasing the Type I error rate.

\section{Results}

\section{Relative habitat specialization}

214 The top three principal components (PCs) accounted for $57 \%$ of the variance (see

215 Supplementary material Table A4 for details of the loadings and correlation of habitat

216 variables and principal components). Some of the highest loading habitat variables are plotted

217 with principal components and are shown in Supplementary material Figure A1 to facilitate

218 interpretation. The first principal component shows positive relationships with tree density,

219 diversity and height: habitat characteristics that could serve as proxies for habitat

220 quality/structure (i.e. higher scores indicating forests or denser woodlands). The latitude of

221 habitats and the index for bush fires loaded positively on principal component 2 whereas

222 shrub density/height, ground vegetation cover, and tree height all showed an inverse

223 relationship with principal component 2. These relationships appear to reflect the latitudinal

224 gradient that is characteristic of the Afrotropical environment i.e. shorter and sparser

225 vegetation associated also with a higher frequency of bush fires in the open and usually more

226 arid savannah habitats which occur at higher and more northern latitudes. Grass height and

227 the presence of livestock dung showed positive and inverse relationships with principal

228 component 3 respectively. There was also a weak positive relationship of lopped trees with

229 principal component 3. These relationships appear to represent habitat disturbance i.e. areas

230 with short grass also associated with higher levels of grazing and with more lopped trees - an

231 additional activity associated with grazing. Thus principal components 1, 2 and 3 were taken 
as indices to represent the structure/quality, latitude/geographical distribution and level of

233 anthropogenic disturbance of habitats respectively.

234 Habitat specialization scores calculated from the PCA scores for all species are shown in

235 Table 1. The differences in HS scores derived from principal component 1 and principal component 3 (i.e. average habitat specialization scores for structure/quality and level of anthropogenic disturbance of habitats) between Palearctic migrant and Afrotropical resident species were not statistically significant (mean PC1 HS score for migrants 0.56 and residents 0.57, $t$-test: $t=0.1$, d.f. $=17.4, P=0.92$ and mean PC3 HS score for migrants 0.67 and

240 residents $0.54, t$-test: $t=-1.3$, d.f. $=15.4, P=0.21)$. Palearctic migrants however had a significantly higher HS score for principal component 2 i.e. were more generalist and occupied a relatively larger latitudinal range compared to the Afrotropical resident species (mean PC2 HS score for migrants 0.64 and residents 0.37 ; $t$-test: $t=-2.4$, d.f. $=11.1, P=$ 0.03). Relative distributions of the HS scores for all species in both residency groups are shown in Figure 2.

The HS scores derived from the 13 unsummarised habitat variables were also not significantly different between resident and migratory birds except for Latitude (Table 2) where migratory birds had significantly higher scores (i.e. were generalists and occurred over a wider latitudinal range) compared to Afrotropical resident birds $(t=-3.3$, d.f. $=16.5, P=$ 0.005); note however that this $P$ - value is just above the new threshold value after a Bonferroni correction is applied (i.e. 0.05/13 $=0.004$ ).

\section{Discussion}

253 Our results suggest that Palearctic migrants and Afrotropical resident species in the Guinea savannah in Nigeria are similar in their degree of generalism or specialization with respect to habitat quality/structure (principal component 1) and disturbance (principal component 3).

256 However, there was some evidence of greater flexibility due to a significant tendency for the 
Palearctic migrants to occupy habitats over a significantly wider latitudinal range (principal component 2) in the study area compared to their Afrotropical resident counterparts.

259 Although the PCA model only explained $57 \%$ of variance, the analysis of individual variables

260 also confirmed that there was no strong evidence for differences in breadth of habitat 261 occupancy across almost all of the gradients considered apart from latitude. Our results are 262 unlikely to be confounded by detectability differences between the two groups because 263 species in the two groups, on average, were recorded at similar distances and so it seems reasonable to conclude that migrants and residents occupy habitats in a broadly similar way.

265 The observations in this study of habitat overlaps and similarity in habitat occupancy provide additional evidence for the emergent view of Palearctic migrants as integral, rather than marginal or peripheral components of the tropical avian communities (Salewski and Jones 2006). Earlier studies tackling the question of coexistence between migrants and resident species with the aim to find evidence for greater flexibility and generalism in the migratory species/individuals often ascribed a great significance to the role of competitive interactions between these groups in shaping these communities (Herrera 1978, Sinclair 1978, Leisler 1992). This assumption greatly influenced the description of migrants as 'invading', 'lessdominant and flexible' members in Afrotropical avian communities, further promoting the idea that migrants also resorted to using more open and diverse habitats in marginal and peripheral parts of the vegetation in order to coexist with the more 'dominant' resident species (Salewski and Jones 2006). However, most of these studies investigating the impacts of competitive interactions on the dynamics of coexistence of these species, as in this study also, have tended to report significant overlaps in habitat occupancy and with little evidence of direct interspecific competition (Leisler 1992, Salewski, et al. 2003, Salewski, et al. 2007,

280 Wilson and Cresswell 2007, Jones, et al. 2010, Wilson and Cresswell 2010). It seems therefore that any impacts of competition in shaping these avian communities may have 
negligible and less detectible (Salewski and Jones 2006). Furthermore, reported evidence of

284 migrants using the presence of temperate resident species as cues in selecting profitable

285 breeding sites rather than avoiding them (Forsman, et al. 2002, Mönkkönen, et al. 2004,

286 Forsman, et al. 2009) suggest that habitat overlaps between migrants and ecologically similar

287 resident species in the tropics should perhaps also be expected. The possibility of

288 heterospecific attraction for migrants in influencing community structures in the tropics is

289 thus well worth investigating.

290 Despite the similarities in habitat occupancy, the observed tendency for Palearctic migrants to

291 occupy these habitats over a significantly wider latitudinal range compared to their

292 Afrotropical resident counterparts does fit with the expectation of generalism and ecological

293 flexibility for migratory species. This may be related to their dispersal capabilities which

294 often also means that they tend to respond mainly to spatial and other factors related to patch

295 dynamics and usually at larger scales than more specialized species (Morris 1996, Shubha, et

296 al. 2009).

297 The utilization of relatively larger ranges by generalist species is also sometimes explained

298 with the suggestion that coexistence with competitors may be fostered by their exploitation of margins and underutilised conditions in-between habitats already occupied by multiple

300 specialized competitors (Morris 1996, Sinclair 1978). The ability of migrants to

301 opportunistically track temporary insect abundance brought about by the initial localised rainstorms during the short rainy season in Central-East Africa (a strategy not used by most of their resident counterparts) may be an example of this. However, overlaps in habitat use between residents and migrants have also been reported in this region from areas of superabundance of food resources (Sinclair 1978). Furthermore, in West Africa, migrants arrive at the end of the rains when the general conditions progressively get drier, particularly in more northern areas (Nicholson, et al. 1990, Schneider, et al. 2014). There is thus an important contrast in the ecological conditions between the regions with the opportunity for 
opportunistic niches and increased food supply arising only in East Africa - yet Palearctic

310 migrants coexist and occupy both regions to similar degrees.

311 Other factors besides competitive interactions may give rise to generalist traits in migrants

312 and explain the tendency for migrants to occupy relatively larger ranges. Some authors

313 (Levey and Stiles 1992, Salewski and Jones 2006, Cresswell 2014) have argued that the

314 ecological flexibility often expected (and that is strongly suggested in this study) for migrants

315 could actually be a fundamental requirement for the evolution and maintenance of migration

316 in the first place. Cresswell (2014), for example, suggests that stochastic events when an

317 individual migrates for the first time could lead to the spread of passage and wintering sites

318 over wide areas, across suitable and not so suitable habitats. If this is the case, then ecological

319 flexibility and generalism would be vital in promoting survival of these naive young birds

320 that would not have prior knowledge of the location of localised habitats on their initial

321 arrival in the savannah zone of Africa. In line with this argument, one may draw parallels to

322 introduced or invading species where similar generalist traits and mechanisms have been

323 shown to significantly contribute to the successful establishment of such organisms to novel

324 environments (Martin and Fitzgerald 2005, Wright, et al. 2010).

325 In conclusion, our observation of the presence/absence of migrants and ecologically similar

326 residents across habitats in a tropical savannah in Nigeria mainly indicate that migrants and

327 residents occupied similar habitat types although migrants had a tendency to occupy habitats

328 over larger spatial scales. This suggests that migrants are probably generalists in the breadth

329 of habitats that they occupy, but not particularly more so than taxonomically similar resident

330 species. Our use of presence/absence data only allowed us to report overlaps and similarities

331 in habitat occupancy between these species groups. A better understanding of the underlying

332 mechanisms of their coexistence will however require investigation also of the interactions

333 between these species, their relative densities in areas of overlaps, foraging behaviour and

334 even the fitness consequences of co-occupancy or habitat segregation. But regardless of the 
335 mechanism, generalism itself in migrants has implications for their population dynamics. As

336 generalists, migrants may be expected to show some resilience especially in dealing with

337 local and small scale changes on their wintering grounds such that these are unlikely to be the

338 primary limiting factor in their population dynamics for many migrant species. This

339 conclusion is particularly relevant considering the widespread and ongoing declines in the

340 populations of Palearctic migrants (Vickery, et al. 2014). Put simply - our study provides

341 additional evidence that habitat availability in Africa may not be limiting for many migrant

342 species.

\section{Acknowledgments}

344 We are grateful to the Leventis Conservation Foundation for funding this research and wish

345 also to acknowledge and thank staff and field assistants at the A.P. Leventis Ornithological

346 Research Institute (APLORI), Jos, Nigeria for help with field travel and logistics. Many

347 thanks also to all the local communities for hospitality and permission to work on their land.

348 Many thanks also to Fidel Atuo for help with producing the map; to Shiiwua Manu, Silke

349 Bauer and two other reviewers for helpful comments on the manuscript. This is publication

350 number $\mathrm{xx}$ (number to be added in the proof stage) from APLORI. 
352

353

354

355

356

357

358

359

360

361

362

363

364

365

366

367

368

369

370

371

372

373

374

375

376

377

378

379

380

381

382

383

384

385

386

387

388

389

390

\section{References}

Abbas, I.I. (2009) An overview of land cover changes in Nigeria, 1975 - 2005. Journal of Geography and Regional Planning 2: 062-065.

Adegbola, A.A. \& Onayinka, E.A.O. (1976) A review of range management problems in the southern Guinea and derived savanna zones of Nigeria. Tropical Grasslands 10: 41-51.

Atkinson, P.W., Adams, W.M., Brouwer, J., Buchanan, G., Cheke, R.A., Cresswell, W., Hewson, C.M., Hulme, M.F., Manvell, A., Sheehan, D.K., Small, R.D.S., Sutherland, W.J. \& Vickery, J.A. (2014) Defining the key wintering habitats in the Sahel for declining African-Eurasian migrants using expert assessment. Bird Conservation International 24: 477 - 491.

Baillie, S. \& Peach, W. (1992) Population limitation in Palaearctic-African migrant passerines. Ibis 134: 120 - 132.

Clavel, J., Julliard, R. \& Devictor, V. (2011) Worldwide decline of specialist species: toward a global functional homogenization? Frontiers in Ecology and the Environment 9: 222-228.

Cresswell, W. (2014) Migratory connectivity of Palaearctic-African migratory birds and their responses to environmental change: the serial residency hypothesis. Ibis 156: 493-510.

FORMECU (1998) Assessment of Vegetation and Land Use Changes in Nigeria between 1978 and 1993.Geomatics International Inc., Beak Consultants Limited of Canada and Unilag Consults Nigeria, Federal Department of Forestry, Abuja, Nigeria.

Forsman, J.T., Hjernquist, M.B. \& Gustafsson, L. (2009) Experimental evidence for the use of density based interspecific social information in forest birds. Ecography 32: $539-545$.

Forsman, J.T., Seppänen, J.T. \& Mönkkönen, M. (2002) Positive Fitness Consequences of Interspecific Interaction with a Potential Competitor. Proceedings: Biological Sciences 269: 1619-1623.

Fry, C.H., Keith, S. \& Urban, E.K. (2000) The Birds of Africa. Academic Press, London, UK.

Herrera, C.M. (1978) Ecological Correlates of Residence and Non-Residence in a Mediterranean Passerine Bird Community. Journal of Animal Ecology 47: 871-890.

Jones, P., Salewski, V., Vickery, J. \& Mapaure, I. (2010) Habitat use and densities of coexisting migrant Willow Warblers Phylloscopus trochilus and resident eremomelas Eremomela spp. in Zimbabwe. Bird Study 57: 44-55.

Julliard, R., Clavel, J., Devictor, V., Jiguet, F. \& Couvet, D. (2006) Spatial segregation of specialists and generalists in bird communities. Ecol. Lett. 9: 1237-1244.

Leisler, B. (1992) Habitat selection and coexistence of migrants and Afrotropical residents. Ibis 134: 77-82. 
Levey, D.J. \& Stiles, F.G. (1992) Evolutionary precursors of long-distnace migrationresource availability and movement patterns in Neotropical landbirds. American Naturalist 140: 447-476.

MacArthur, R.H. (1972) Geographical Ecology. Harper \& Row Publishers Inc., New York, USA.

Martin, L.B. \& Fitzgerald, L. (2005) A taste for novelty in invading house sparrows, Passer domesticus. Behavioral Ecology 16: 702-707.

Mönkkönen, M., Forsman, J.T. \& Thomson, R.L. (2004) Qualitative geographical variation in interspecific interactions. Ecography 27: 112 - 118.

Morris, D.W. (1996) Coexistence of Specialist and Generalist Rodents Via Habitat Selection. Ecology 77: 2352-2364.

Nicholson, S.E., Davenport, M.L. \& Malo, A.R. (1990) A comparison of the vegetation response to rainfall in the Sahel and East Africa, using Normalized Difference Vegetation Index from NOAA AVHRR. Climate change 17: 209-241.

Ockendon, N., Hewson, C.M., Johnston, A. \& Atkinson, P.W. (2012) Declines in Britishbreeding populations of Afro-Palaearctic migrant birds are linked to bioclimatic wintering zone in Africa, possibly via constraints on arrival time advancement. Bird Study 59: 111-125.

Ockendon, N., Johnston, A. \& Baillie, S.R. (2014) Rainfall on wintering grounds affects population change in many species of Afro-Palaearctic migrants. Journal of Ornithology 155: 905917.

Salewski, V., Almasi, B., Heuman, A., Thoma, M. \& Schlageter, A. (2007) Agonistic behaviour of Palaearctic passerine migrants at a stopover site suggests interference competition. Ostrich 78: 349-355.

Salewski, V., Bairlein, F. \& Leisler, B. (2002) Different wintering strategies of two Palearctic migrants in West Africa - a consequence of foraging strategies? Ibis 144: $85-93$.

Salewski, V., Bairlein, F. \& Leisler, B. (2003) Niche partitioning of two Palearctic passerine migrants with Afrotropical residents in their West African winter quarters. Behavioral Ecology 14: 493-502.

Salewski, V. \& Jones, P. (2006) Palearctic passerines in Afrotropical environments: a review. Journal of Ornithology 147: 192-201.

Schneider, T., Bischoff, T. \& Haug, G.H. (2014) Migrations and dynamics of the intertropical convergence zone. Nature 513: 45-53.

Shubha, N.P., Jurek, K. \& Karl, C. (2009) Contrasts between habitat generalists and specialists: an empirical extension to the basic metacommunity framework. Ecology 90: $2253-2262$.

Sinclair, A.R.E. (1978) Factors affecting the food supply and breeding season of resident birds and movements of Palaerctic migrants in a tropical African savannah. Ibis 120: 480-497.

Sokolov, V., Ehrich, D., Yoccoz, N.G., Sokolov, A. \& Lecomte, N. (2012) Bird communities of the arctic shrub tundra of Yamal: habitat specialists and generalists. PLoS One 7: e50335.

Urban, E.K., Fry, C.H. \& Keith, S. (1992) The Birds of Africa. Academic Press, London, UK. 
Urban, E.K., Fry, C.H. \& Keith, S. (1997) The Birds of Africa. Academic Press. Gregory, R.D. (2014) The decline of Afro-Palaearctic migrants and an assessment of potential causes. Ibis 156: 1 - 22.

Walther, B.A., Van Niekerk, A. \& Rahbek, C. (2011) Long-term population declines of Palearctic passerine migrant birds: a signal from the Sahel? BOU Proceedings - The Ecology \& Conservation of Migratory Birds; http://www.bou.org.uk/bouprocnet/migratory-birds/walther-etal.pdf

Wilson, D.S. \& Yoshimura, J. (1994) On the Coexistence of Specialists and Generalists. Am. Nat. 144: 692-707.

Wilson, J.M. \& Cresswell, W. (2010) Densities of Palearctic warblers and Afrotropical species within the same guild in Sahelian West Africa. Ostrich 81: 225-232.

Wilson, J.M. \& Cresswell, W.R.L. (2007) Identification of potentially competing Afrotropical and Palaearctic bird species in the Sahel. Ostrich,78: 363-368.

Wright, T.F., Eberhard, J.R. \& Hobson, E.A. (2010) Behavioral flexibility and species invasions: the adaptive flexibility hypothesis. Ethology Ecology \& Evolution 22: 393404. 


\section{SUPPORTING INFORMATION}

457 Additional supporting information may be found in the supplementary materials and include:

458 Table A1. A list of all surveyed sites and transects with geographical coordinates arranged 459 and listed from North to South (top to bottom) along with their survey dates.

460 Table A2. A description of all vegetation and habitat quality and geographical variables

461 collected at each point along every transect at each survey site.

462 Table A3. A list of all 35 species of both Afrotropical resident and Palearctic migrant species 463 recorded and initially considered for analysis with information about the number of points

464 and transects from where they were observed as well as average abundance and migratory 465 status.

466 Table A4. Habitat variable loadings on the top three principal components after the principal 467 components analysis

468 Figure A1. Illustration of the relationship of some of the top loading habitat variables on the 469 first three principal components.

470

471

472 
474 Table 1. All 25 species included in the analysis showing habitat specialization scores (HS 475 scores) derived from each of the three principal components (PC 1 - 3 i.e. habitat quality, 476 distribution and disturbance) and their residency status ( $\mathrm{R}=$ Afrotropical Resident, 477 M=Palearctic migrant). See Supplementary material Table A3 for scientific names.

\begin{tabular}{ccccc}
\hline \multirow{2}{*}{ Common name } & HSS & HSS & HSS & Migratory \\
& $(\mathrm{PC} 1)$ & $(\mathrm{PC} 2)$ & $(\mathrm{PC} 3)$ & status \\
\hline
\end{tabular}

\section{Pipits and likes}

Tree Pipit

Plain-back Pipit

0.0

0.6

0.7

M

Yellow Wagtail

0.4

0.3

0.7

$\mathrm{R}$

Yellow-throated Longclaw

0.2

0.8

0.8

$\mathrm{M}$

Chats and likes

African Thrush

Snowy-crowned Robin-chat

0.7

0.5

0.6

0.2

$\mathrm{R}$

Whinchat

0.8

0.2

0.2

$\mathrm{R}$

0.6

0.6

0.6

$\mathrm{R}$

African Stonechat

0.1

0.3

0.0

$\mathrm{M}$

Familiar Chat

0.7

0.3

0.5

$\mathrm{R}$

\section{Warblers and likes}

Garden Warbler

Common Whitethroat

$\begin{array}{ll}0.3 & 0.9\end{array}$

\section{7}

0.6

0.0

0.3

M

Willow Warbler

0.8

0.8

1.0

M

Senegal Eremomela

0.7

0.4

0.9

M

Northern Crombec

0.8

1.0

0.4

$\mathrm{R}$

Grey-backed Camaroptera

0.7

0.4

0.8

Tawny-flanked Prinia

1.0

0.4

0.7

Dorst's Cisticola

0.6

0.4

0.6

Rock-loving Cisticola

0.1

0.0

0.3

$\mathrm{R}$

$\mathrm{R}$

$\mathrm{R}$

$\mathrm{R}$

$\mathrm{R}$

\section{Flycatchers and likes}

Northern Black Flycatcher

0.5

0.1

0.6

$\mathrm{R}$

Spotted Flycatcher

0.4

0.7

0.4

$\mathrm{M}$

Pale Flycatcher

0.7

0.5

0.4

$\mathrm{R}$

Pied Flycatcher

0.5

0.8

0.8

$\mathrm{M}$

African Paradise Flycatcher

0.7

0.4

0.8

$\mathrm{R}$

Senegal Batis

0.7

0.4

0.8

$\mathrm{R}$

Yellow-billed Shrike

$0.7 \quad 0.4$

0.8

$\mathrm{R}$ 
Table 2. Average Habitat Specialization scores derived from the 13 unsummarised habitat variables of Afrotropical and Palearctic migratory birds with results of tests of differences between the residency groups for each variable.

\begin{tabular}{|c|c|c|c|c|c|}
\hline \multirow[b]{2}{*}{ Habitat Variable } & \multicolumn{2}{|c|}{ Mean HS score } & \multirow[b]{2}{*}{$t$-value } & \multirow[b]{2}{*}{ d.f. } & \multirow[b]{2}{*}{$\boldsymbol{P}$} \\
\hline & $\begin{array}{c}\text { Afrotropical } \\
\text { species }\end{array}$ & $\begin{array}{l}\text { Palearctic } \\
\text { migrants }\end{array}$ & & & \\
\hline \multicolumn{6}{|l|}{ Vegetation cover } \\
\hline Number of trees & 0.5 & 0.5 & -0.2 & 14.3 & 0.82 \\
\hline Tree species richness & 0.6 & 0.5 & 0.7 & 21.9 & 0.51 \\
\hline Number of shrubs & 0.2 & 0.3 & -1.3 & 8.2 & 0.23 \\
\hline Ground vegetation cover & 0.5 & 0.6 & -1.8 & 16.2 & 0.10 \\
\hline \multicolumn{6}{|l|}{$\begin{array}{l}\text { Vegetation height profile } \\
\text { \& structure }\end{array}$} \\
\hline Dominant vegetation layer & 0.5 & 0.5 & -0.1 & 21.9 & 0.89 \\
\hline Tree height & 0.5 & 0.6 & -1.7 & 18.6 & 0.11 \\
\hline Shrub height & 0.5 & 0.6 & -1.4 & 15.4 & 0.18 \\
\hline Grass height & 0.7 & 0.5 & 1.3 & 11.7 & 0.22 \\
\hline \multicolumn{6}{|l|}{ Habitat disturbance } \\
\hline Number of loped trees & 0.4 & 0.3 & 0.7 & 15.6 & 0.51 \\
\hline Cattle dung (grazing) & 0.6 & 0.6 & -0.1 & 13.4 & 0.92 \\
\hline Number of tree stumps & 0.2 & 0.1 & 1.4 & 22.9 & 0.19 \\
\hline Bush burning & 0.8 & 0.8 & 0.2 & 20.9 & 0.86 \\
\hline \multicolumn{6}{|l|}{ Habitat location } \\
\hline Latitude & 0.5 & 0.8 & -3.3 & 16.5 & * 0.005 \\
\hline
\end{tabular}




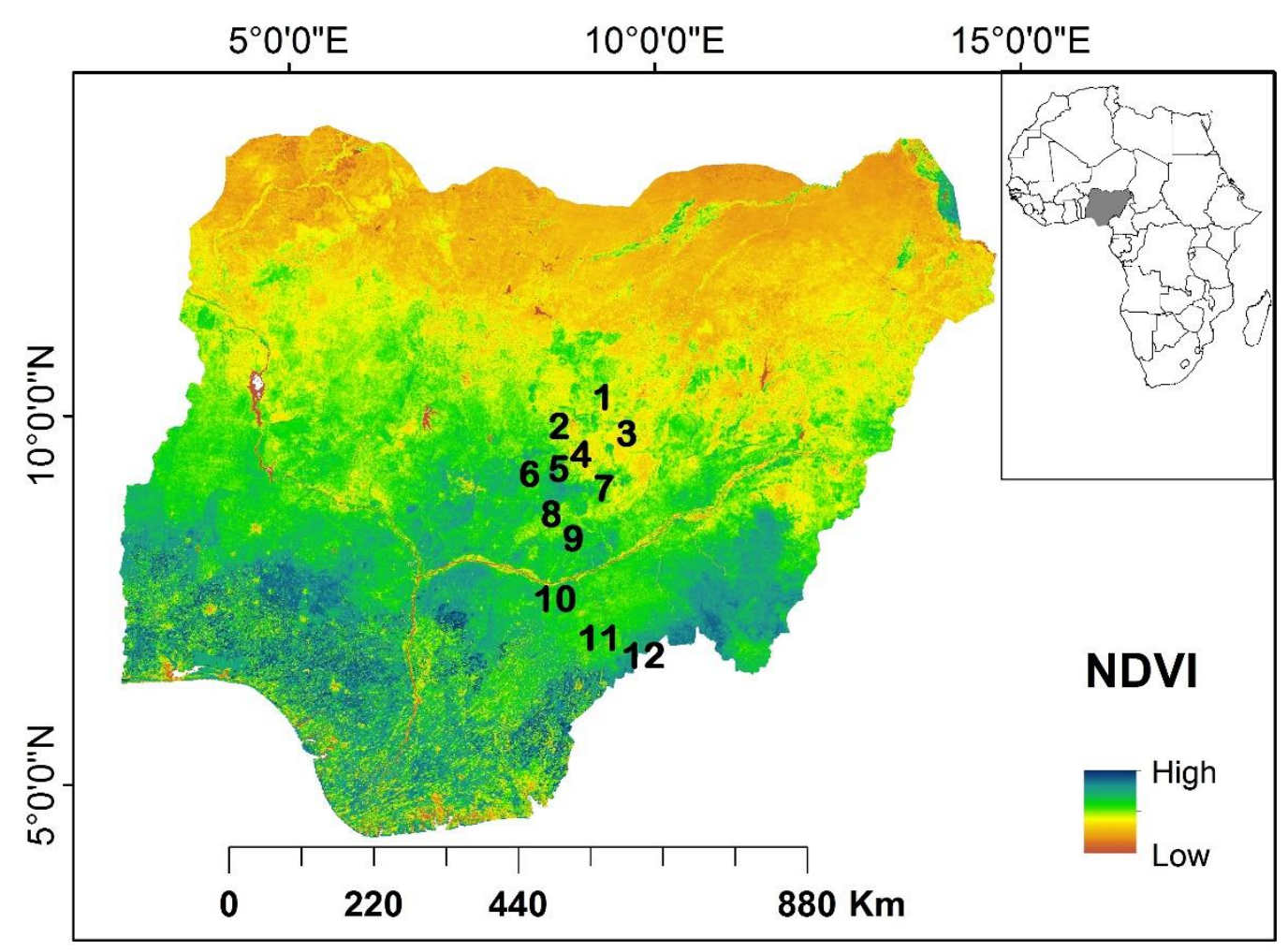

490 Figure 1. An NDVI map of Nigeria at the end of the rainy season (November-December

491 2012) showing location of survey sites. Numbers on map correspond to site number shown in

492 Table 1. A map of Africa is shown as an inset at the top right corner of the figure to show the 493 location of Nigeria within Africa. 
Habitat quality

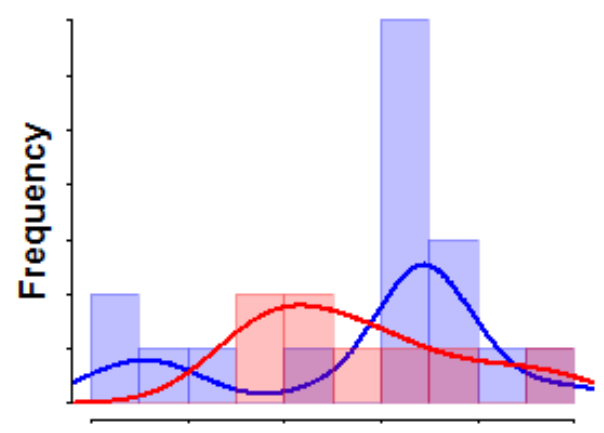

$\begin{array}{llllll}0.0 & 0.2 & 0.4 & 0.6 & 0.8 & 1.0\end{array}$

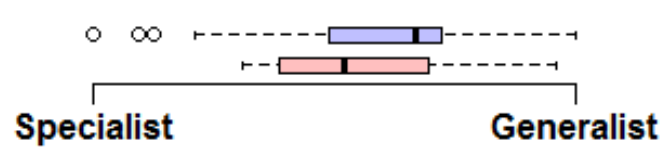

Habitat Specialization
Latitudinal distribution
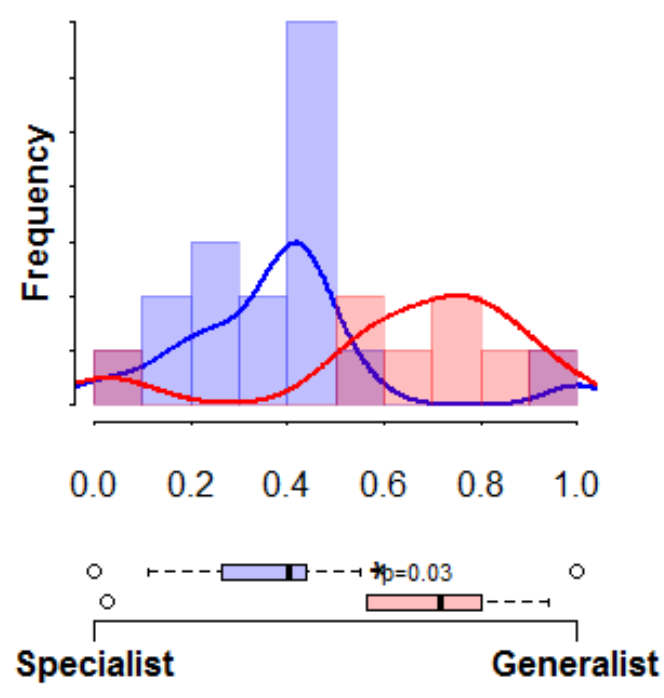

Habitat Specialization
Anthropogenic disturbance
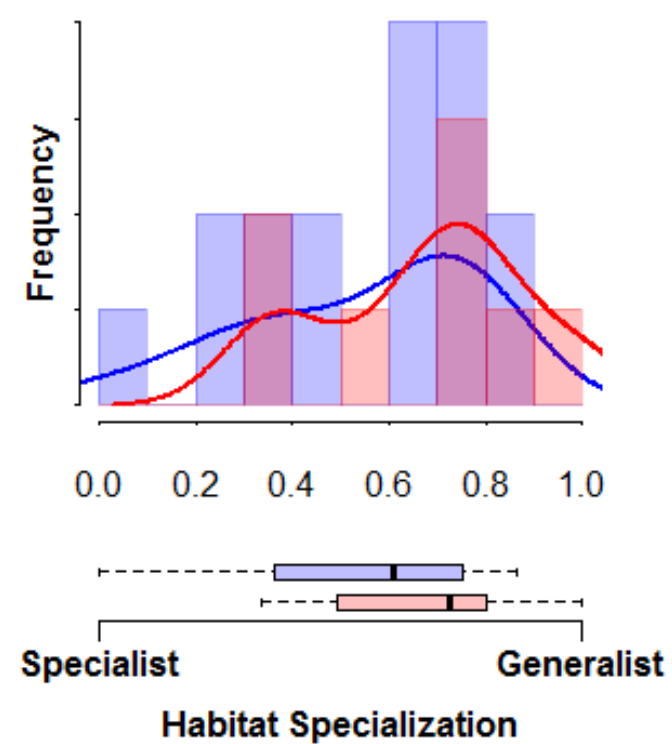

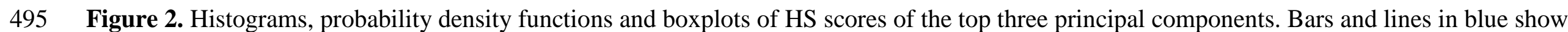

496 distribution of HS scores for Afrotropical resident species while red bars and lines are for Palearctic migrants. Some overlaps can be seen for

497 instances where scores are similar and not statistically different (far left and right plots) for HS scores (habitat quality \& anthropogenic

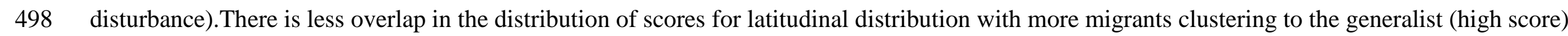

499 end of the scale (middle plot) 
Table A1. List of all surveyed sites and transects with geographical coordinates arranged and listed from North to South (top to bottom) and survey dates. Winter $1=$ Feb - May 2012;

Winter 2 = Oct 2012 - Mar 2013; Winter 3 = Oct 2013 - Feb 2014.

\begin{tabular}{|c|c|c|c|c|c|c|}
\hline \multirow[b]{2}{*}{$\begin{array}{l}\text { Site } \\
\text { No. }\end{array}$} & \multirow[b]{2}{*}{ Site } & \multirow[b]{2}{*}{$\begin{array}{l}\text { Transect } \\
\text { number }\end{array}$} & \multirow[b]{2}{*}{$\begin{array}{c}\text { Latitude } \\
\left({ }^{\circ} \mathrm{N}\right)\end{array}$} & \multirow[b]{2}{*}{$\begin{array}{c}\text { Longitude } \\
\left({ }^{\circ} E\right)\end{array}$} & \multicolumn{2}{|c|}{ Survey Dates } \\
\hline & & & & & $\begin{array}{l}\text { Winter } 1 \\
2011 / 12\end{array}$ & $\begin{array}{l}\text { Winter } 2 \\
2012 / 13\end{array}$ \\
\hline \multirow[t]{4}{*}{1} & $+\mathrm{Jos}$ & 1 & 9.8794 & 8.9759 & 9 Feb, 6 Mar, 6 Apr, 1 May & 8 Oct, 10 Dec, 7 Feb, 11 Mar \\
\hline & & 2 & 9.8587 & 8.9910 & 10 Feb, 7 Mar, 7 Apr, 2 May & 9 Oct, 11 Dec, 8 Feb, 12 Mar \\
\hline & & 3 & 9.8359 & 8.9762 & 11 Feb, 8 Mar, 9 Apr, 3 May & 10 Oct, 13 Dec, 9 Feb, 13 Mar \\
\hline & & 4 & 9.8170 & 8.9046 & - & 11 Feb, 14 March \\
\hline \multirow[t]{3}{*}{2} & +Kagoro & 1 & 9.5694 & 8.3703 & $20 \mathrm{Feb}, 21 \mathrm{Mar}, 18 \mathrm{Apr}, 11 \mathrm{May}$ & $5 \mathrm{Oct}, 4 \mathrm{Feb}, 15 \mathrm{Mar}$ \\
\hline & & 2 & 9.5641 & 8.3593 & 21 Feb, 22 Mar, 19 Apr, 12 May & 6 Oct, 5 Feb, 16 Mar \\
\hline & & 3 & 9.5280 & 8.3706 & 22 Feb, 23 Mar, 20 Apr, 13 May & 7 Oct, 6 Feb, 17 Mar \\
\hline \multirow[t]{3}{*}{3} & *Aboro & 1 & 9.4875 & 8.5914 & 17 Feb, 18 Mar, 15 Apr, 8 May & - \\
\hline & & 2 & 9.4841 & 8.5844 & 18 Feb, 19 Mar, 16 Apr, 9 May & - \\
\hline & & 3 & 9.4825 & 8.5979 & 19 Feb, 20 Mar, 17 Apr, 10 May & - \\
\hline \multirow[t]{3}{*}{4} & *Pankshin & 1 & 9.3900 & 9.2963 & 6 Feb, 3 Mar, 3 Apr, 27 Apr & - \\
\hline & & 2 & 9.3683 & 9.5308 & 7 Feb, 4 Mar, 4 Apr, 28 Apr & - \\
\hline & & 3 & 9.3513 & 9.4311 & 8 Feb, 5 Mar, 29 Apr, & - \\
\hline \multirow[t]{3}{*}{5} & *Farin Ruwa & 1 & 9.1078 & 8.7380 & $14 \mathrm{Feb}, 15 \mathrm{Mar}, 12 \mathrm{Apr}, 5$ May & - \\
\hline & & 2 & 9.1029 & 8.7254 & 15 Feb, 16 Mar, 13 Apr, 6 May & - \\
\hline & & 3 & 9.0976 & 8.7405 & 16 Feb, 17 Mar, 14 Apr, 7 May & - \\
\hline \multirow[t]{3}{*}{6} & $\neq$ Endehu & 1 & 8.8415 & 8.4592 & $8 \mathrm{Dec}, 1 \mathrm{Feb}, 18 \mathrm{Mar}$ & - \\
\hline & & 2 & 8.8375 & 8.4855 & 9 Dec, 2 Feb, 19 Mar & - \\
\hline & & 3 & 8.8302 & 8.4518 & - , 3 Feb, 20 Mar & - \\
\hline \multirow[t]{3}{*}{7} & +Pandam & 1 & 8.6494 & 8.9746 & $2 \mathrm{Feb}, 29 \mathrm{Feb}, 31 \mathrm{Mar}, 24 \mathrm{Apr}$ & 31 Oct, 29 Jan, 21 Feb \\
\hline & & 2 & 8.6342 & 8.9256 & 3 Feb, 1 Mar, 1 Apr, 25 Apr & 1 Nov, 30 Jan, 22 Feb \\
\hline & & 3 & 8.6209 & 8.9652 & 4 Feb, 2 Mar, 2 Apr, 26 Apr & 2 Nov, 31 Jan, 23 Feb \\
\hline \multirow[t]{2}{*}{8} & $\neq$ Akanga & 1 & 8.3016 & 8.5606 & - & 3 Nov \\
\hline & & 2 & 8.3008 & 8.5629 & - & 4 Nov, 28 Jan \\
\hline \multirow[t]{3}{*}{9} & $\neq$ Makurdi & 1 & 7.9686 & 8.5678 & - & 6 Nov, 25 Jan, 25 Mar \\
\hline & & 2 & 7.8045 & 8.6168 & - & 7 Nov, 26 Jan, 26 Mar \\
\hline & & 3 & 7.4605 & 8.5851 & - & 8 Nov, 27 Jan, 27 Mar \\
\hline \multirow[t]{4}{*}{10} & $\neq$ đshongo & 1 & 7.1521 & 8.8408 & - & 29 Nov, 22 Jan, 28 Mar \\
\hline & & 2 & 7.1517 & 8.8368 & - & 30 Nov, 23 Jan, 29 Mar \\
\hline & & 3 & 7.1503 & 8.8386 & - & 1 Dec, 24 Jan, 30 Mar \\
\hline & & 4 & 7.1369 & 8.8409 & - & $2 \mathrm{Dec}$ \\
\hline \multirow[t]{3}{*}{11} & ¥Obudu2 & 1 & 6.6221 & 9.3549 & - & 3 Dec, 19 Jan, 31 Mar \\
\hline & & 2 & 6.6189 & 9.3391 & - & 4 Dec, 20 Jan, 1 Apr \\
\hline & & 3 & 6.4991 & 9.4280 & - & 5 Dec, 21 Jan, 2 Apr \\
\hline \multirow[t]{3}{*}{12} & $\neq$ Obudu & 1 & 6.3815 & 9.3769 & - & 10 Nov, 16 Jan, 3 Apr \\
\hline & & 2 & 6.3754 & 9.3751 & - & 11 Nov, 17 Jan, 4 Apr \\
\hline & & 3 & 6.3703 & 9.3945 & - & 12 Nov, 18 Jan, 5 Apr \\
\hline
\end{tabular}

+ Sites surveyed during both winter seasons

* Sites surveyed in the first winter season only

$\neq$ Sites surveyed in the second winter season only 
Table A2. All vegetation and habitat quality and geographical variables collected at each point along every transect at each survey site

\section{Variables Description}

Tree density $\quad$ Number of trees (plants $>1 \mathrm{~m}$ height and diameter at breast height $>10 \mathrm{~cm}$ )within a $25 \mathrm{~m}$ radius circular plot centred at the points where bird counts had been recorded

\begin{tabular}{ll} 
Tree species richness & Number of different species of trees present in the plot \\
\hline $\begin{array}{l}\text { Dominant vegetation } \\
\text { layer }\end{array}$ & $\begin{array}{l}\text { A score of } 1-4 \text { if dominant vegetation layer in the } 25 \mathrm{~m} \text { circular } \\
\text { plot was bare or dominated by grasses, shrubs or trees } \\
\text { respectively }\end{array}$
\end{tabular}

Tree height Scored between 1-4 if height of trees within a $25 \mathrm{~m}$ radius of the point ranged between $<3 \mathrm{~m}, 3-7 \mathrm{~m}, 7-14 \mathrm{~m},>14 \mathrm{~m}$ respectively

Shrub height Scores of $1-4$ if height of shrubs within a 25 m radius of the point ranged between $<0.5 \mathrm{~m}, 0.5-3 \mathrm{~m}, 3-5 \mathrm{~m},>5 \mathrm{~m}$ respectively

Grass height $\quad$ Scores of $1-4$ if height of grass within a $25 \mathrm{~m}$ radius of the observer mostly ranged between $<0.03-0.3 \mathrm{~m}, 0.3-1 \mathrm{~m}, 3 \mathrm{~m},>3 \mathrm{~m}$ respectively

Lopped trees The number of trees with evidence of lopping to provide fodder for livestock

Canopy cover A percentage estimate of the circular view obscured by the vegetation canopy as viewed through the reverse end of a binoculars

Shrubs

The number of shrubs (plants with multiple stems from the ground surface or with main boles small enough to be grabbed by one hand) in the circular plot

Habitat type Classified as Woodland (no evidence of farming and closed canopy), Open Woodland (no evidence of farming but little to no canopy cover), Wooded Farmland (farmland with retained trees and canopy and hedge vegetation) or Open Farmland (no trees and canopy cover)

Ground vegetation cover

NDVI
1 minus the proportion of bare ground visible within the circular plot

Normalised Difference Vegetation Index extracted at the coordinates of each point, derived from the Moderate Resolution Imaging Spectroradiometer (MODIS) sensor at $250 \mathrm{~m}$ spatial resolution, every 16 days and downloaded from the International Research Institute for Climate and Society, Earth Institute, Colombia University website http://iri.columbia.edu/. NDVI was extracted for the 16 day period closest to the survey date of the point.

Stumps
The number of tree stumps after tree or shrub felling, counted within the $25 \mathrm{~m}$ circular plot 

ground and shrub vegetation within $25 \mathrm{~m}$ radius of point

Grazing/Livestock dung Scored as 0 or 1 if there was any evidence of livestock dung

Latitude

Obtained at each point in decimal degrees from the Garmin 62 GPS 
Table A3. List of all 35 species of both Afrotropical resident and Palearctic migrant species recorded and initially considered for analysis. (Migratory status: $\mathrm{R}=\mathrm{A}$ frotropical resident, $\mathrm{M}=$ Palearctic migrant). Species not included in analysis are in italics.

\begin{tabular}{|c|c|c|c|c|c|}
\hline Common name & Scientific name & $\begin{array}{c}\text { Number } \\
\text { of points } \\
\text { where } \\
\text { seen }\end{array}$ & $\begin{array}{c}\text { Average } \\
\text { count } \\
\text { over } \\
\text { survey } \\
\text { period } 1\end{array}$ & $\begin{array}{c}\text { Migratory } \\
\text { status }\end{array}$ & $\begin{array}{c}\text { Number } \\
\text { of } \\
\text { transects } \\
\text { where } \\
\text { seen }\end{array}$ \\
\hline Common Sandpiper & Actitis hypoleucos & 5 & 10 & $M$ & 2 \\
\hline Tree Pipit & Anthus trivialis & 40 & 77 & M & 8 \\
\hline Plain-backed Pipit & Anthus leucophrys & 15 & 27 & $\mathrm{R}$ & 7 \\
\hline Yellow Wagtail & Motacilla flava & 14 & 99 & M & 4 \\
\hline $\begin{array}{l}\text { Yellow-throated } \\
\text { Longclaw }\end{array}$ & Macronyx croceus & 17 & 27 & $\mathrm{R}$ & 4 \\
\hline African thrush & Turdus pelios & 81 & 126 & $\mathrm{R}$ & 12 \\
\hline $\begin{array}{l}\text { Snowy-crowned } \\
\text { Robin Chat }\end{array}$ & Cossypha niveicapilla & 11 & 19 & $\mathrm{R}$ & 4 \\
\hline Whinchat & Saxicola rubetra & 158 & 312 & M & 11 \\
\hline African Stonechat & Saxicola torquatus & 22 & 38 & $\mathrm{R}$ & 1 \\
\hline Familiar chat & Cercomel afamiliaris & 22 & 32 & $\mathrm{R}$ & 6 \\
\hline Cliff Chat & $\begin{array}{l}\text { Myrmecocichla } \\
\text { cinnamomeiventris }\end{array}$ & 2 & 4 & $R$ & 1 \\
\hline $\begin{array}{l}\text { Northern Anteater } \\
\text { Chat }\end{array}$ & Myrmecocichla aethiops & 8 & 16 & $R$ & 2 \\
\hline Garden Warbler & Sylvia borin & 16 & 22 & M & 5 \\
\hline
\end{tabular}




\begin{tabular}{|c|c|c|c|c|c|}
\hline $\begin{array}{l}\text { Common } \\
\text { Whitethroat }\end{array}$ & Sylvia communis & 67 & 92 & M & 5 \\
\hline Wood Warbler & Phylloscopus sibilatrix & 8 & 9 & $M$ & 4 \\
\hline Willow Warbler & Phylloscopus trochilus & 82 & 108 & M & 11 \\
\hline Senegal Eremomela & Eremomela pusilla & 101 & 265 & $\mathrm{R}$ & 10 \\
\hline Northern Crombec & Sylvietta brachyura & 14 & 17 & $\mathrm{R}$ & 6 \\
\hline $\begin{array}{l}\text { Grey-backed } \\
\text { Camaroptera }\end{array}$ & Camaroptera brachyura & 52 & 60 & $\mathrm{R}$ & 10 \\
\hline $\begin{array}{l}\text { Tawny-flanked } \\
\text { Prinia }\end{array}$ & Prinia subflava & 89 & 146 & $\mathrm{R}$ & 11 \\
\hline Red-winged Warbler & Heliolais erythropterus & 9 & 16 & $R$ & 6 \\
\hline Dorst's Cisticola & Cisticola guinea & 29 & 43 & $\mathrm{R}$ & 8 \\
\hline $\begin{array}{l}\text { Rock-loving } \\
\text { Cisticola }\end{array}$ & Cisticola aberrans & 12 & 16 & $\mathrm{R}$ & 2 \\
\hline Chubb's Cisticola & Cisticola chubbi & 7 & 12 & $R$ & 1 \\
\hline $\begin{array}{l}\text { Northern Black } \\
\text { Flycatcher }\end{array}$ & Melaenornis edoliodes & 39 & 97 & $\mathrm{R}$ & 7 \\
\hline Spotted Flycatcher & Muscicapa striata & 67 & 149 & M & 9 \\
\hline Pale flycatcher & Melaenornis pallidus & 40 & 76 & $\mathrm{R}$ & 8 \\
\hline Pied Flycatcher & Ficedula hypoleuca & 124 & 152 & M & 10 \\
\hline $\begin{array}{l}\text { African Paradise } \\
\text { Flycatcher }\end{array}$ & Terpsiphone viridis & 53 & 77 & $\mathrm{R}$ & 8 \\
\hline $\begin{array}{l}\text { African Blue } \\
\text { Flycatcher }\end{array}$ & Elminia longicauda & 7 & 11 & $R$ & 2 \\
\hline
\end{tabular}




$\begin{array}{llcccc}\text { Senegal Batis } & \text { Batis senegalensis } & 42 & 70 & \mathrm{R} & 8 \\ \begin{array}{l}\text { Common Wattle-Eye } \\ \text { Poodchat Shrike }\end{array} & \text { Platysteira cyanea } & 6 & 10 & R & 4 \\ \begin{array}{l}\text { Lackinnon's Shrike } \\ \text { Lanius mackinnoni }\end{array} & \text { Corvinella corvina } & 9 & 10 & R & 1 \\ \begin{array}{l}\text { Yellow-billed } \\ \text { Shrike }\end{array} & \text { C } & 26 & 68 & \mathrm{R} & 10\end{array}$

${ }^{1}$ total count of individuals for each species over both winter seasons divided by 2 
Table A4. Habitat variable loadings on the top three principal components after the principal components analysis

\begin{tabular}{|c|c|c|c|c|c|c|c|}
\hline \multirow[t]{2}{*}{ Habitat variables } & \multicolumn{3}{|c|}{ Unrotated loadings } & & \multicolumn{2}{|c|}{$\begin{array}{l}\text { Varimax } \\
\text { loadings }\end{array}$} & \multirow{2}{*}{$\begin{array}{l}\text { rotated } \\
\text { PC3 } \\
\end{array}$} \\
\hline & PC1 & PC2 & PC3 & & PC1 & PC2 & \\
\hline Tree density & 0.36 & -0.29 & 0.22 & & 0.51 & & \\
\hline Loped & 0.24 & 0.11 & -0.17 & & & & -0.36 \\
\hline Livestock dung & 0.23 & 0.11 & -0.58 & & & -0.23 & -0.58 \\
\hline Stump density & 0.24 & 0.03 & -0.02 & & 0.16 & & -0.17 \\
\hline Burning & 0.18 & 0.23 & 0.43 & & 0.14 & 0.49 & 0.17 \\
\hline Shrub density & -0.01 & -0.31 & -0.33 & & & -0.43 & -0.13 \\
\hline Ground veg cover & -0.33 & -0.33 & -0.07 & & & -0.38 & 0.28 \\
\hline Latitude & 0.28 & 0.39 & 0.01 & & & 0.36 & -0.32 \\
\hline Tree diversity & 0.39 & -0.27 & 0.24 & & 0.52 & & \\
\hline Dominant veg layer & 0.38 & -0.24 & 0.02 & & 0.43 & & -0.12 \\
\hline Tree height & 0.30 & -0.33 & 0.06 & & 0.43 & -0.12 & \\
\hline Shrub height & -0.03 & -0.44 & -0.22 & & 0.16 & -0.47 & \\
\hline Grass height & -0.31 & -0.22 & 0.43 & & & & 0.56 \\
\hline Standard deviation & 1.78 & 1.70 & 1.16 & & & & \\
\hline Proportion of & & & & Proportion & & & \\
\hline Variance & 0.24 & 0.22 & 0.10 & Variance & 0.077 & 0.077 & 0.077 \\
\hline Cumulative & & & & Cumulative & & & \\
\hline Proportion & 0.24 & 0.47 & 0.57 & Variance & 0.077 & 0.154 & 0.231 \\
\hline
\end{tabular}



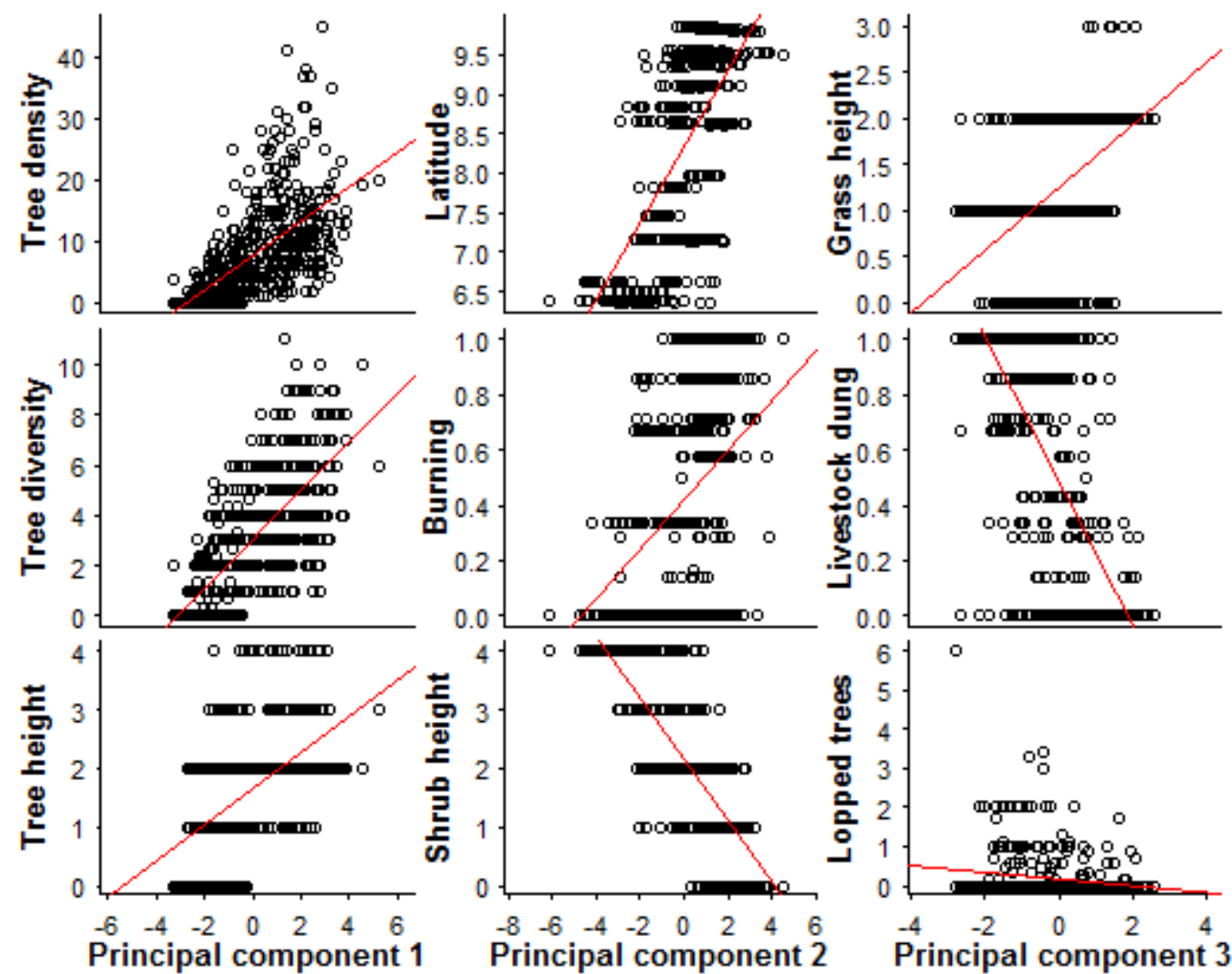

Figure A1. Relationship of some of the top loading habitat variables on the first three principal components. The first column of three plots show positive loadings of tree density, diversity and height (top-bottom respectively) on principal component 1 . The three plots in the middle column show a positive loading of latitude and the index for bush burning and a negative loading of shrub height with principal component 2. In the last column, the three plots show positive loadings of grass height, and negative loadings of livestock dung and density of lopped trees with principal component 3 . 